\title{
Primary sinonasal malignant melanoma: a nationwide study of the Swedish population, 1960-2000*
}

\author{
Mattias Jangard', Johan Hansson², Boel Ragnarsson-Olding² \\ ' Department of Oto-Rhino-Laryngology, Head and Neck Surgery, Karolinska Institutet, Karolinska University Hospital, Stockholm, \\ Sweden \\ ${ }^{2}$ Department of Oncology-Pathology, Karolinska Institutet, Stockholm, Sweden
}

Rhinology 51: 22-30, 2013

DOI:10.4193/Rhino12.075

*Received for publication:

May 8, 2012

Accepted: October 1, 2012

\section{Summary \\ Objective: To establish population-based trends for sinonasal mucosal melanoma (SNMM) in Sweden.}

Methodology/Principal: We identified 186 patients from the Swedish National Cancer Registry diagnosed with primary melanomas arising from the nasal cavity, paranasal sinuses, or both, during the period 1960 through 2000 . Incidence, gender and age, primary anatomical sites, geographic distribution, treatment and survival were investigated.

Results: The age-standardized incidence of SNMM increased significantly during the 41-year-period, with a higher overall incidence for females than males, but with a more rapid increase for males than for females. The incidence increased with age, peaking after the eightieth year in both genders. About $70 \%$ of the cases were clinically amelanotic. The most common primary treatment was surgery. Five-year, disease-specific survival rates were poor for all these patients, but women had a significantly better survival time than men. For both genders the survival rate lengthened during the study period, irrespective of therapeutic strategy.

Conclusion: SNMM is a rare disease, but the incidence in Sweden has increased significantly from 1960 through 2000, although not at the same pace as that of cutaneous malignant melanoma. Both the incidence and the survival were significantly higher in females than in males, but the reason for these gender differences is unknown.

Key words: malignant melanoma, sinonasal, paranasal sinuses, incidence, survival

\section{Introduction}

Malignant melanomas emerging in mucosal membranes (MMM) are rare and generally have a worse prognosis than cutaneous malignant melanomas (CMM). Although the number of CMM continues to increase in many parts of the world, probably in relation to the effects of sun-related behaviour, the incidence of mucosal melanomas such as vulvar and ano-rectal melanoma, shows a more complex pattern with a decreasing ${ }^{(1)}$ or stable ${ }^{(2,3)}$ incidence rate. Only in a single study did mucosal melanomas at a particular site (ano-rectal) show an increasing trend, especially for men ${ }^{(4)}$. Generally, however, MMM do not seem to be increasing, according to recent studies. MMM (eye melanoma not included) account for about $2 \%$ of all melanomas in Sweden (5). Among MMMs registered in the Swedish National Cancer Registry from 1960 to 2009 the most common primary site was the vulva (45\%), followed by the ano-rectal region (27\%), and sinonasal cavities (SNMM) (25\%). Other sites of origin included the oral cavity, vagina, penis, and urethra, in that order. SNMM amount to $1-12 \%$ of all malignant lesions of the nasal tract ${ }^{(6-8)}$. Melanocytes are neuroectodermally derived cells located in the basal layers of the skin, skin adnexa, and some mucosal membranes. Malignant melanomas may arise from melanocytes 
present in the epidermis as well as in certain other tissues, including the nasal mucosa ${ }^{(9)}$. UV light is the major environmental carcinogen in the genesis of $\mathrm{CMM}^{(10)}$. In contrast, the aetiology and predisposing factor(s) of MMMs are unknown. Yet, SNMM may be particularly relevant for studying the risk factors in airborne carcinogens ${ }^{(11)}$.

Here, we focus on primary SNMM, emerging in the nasal cavity and paranasal sinuses. In 1869, Lücke described the first case of malignant melanoma of the nasal cavity ${ }^{(12)}$. He found 'a melanotic sarcoma which arose in the nasal mucous membrane' of a man 52 years of age. Since then, a number of studies have been published describing this rare disease. Most of them are case reports or small series of cases, but few comprise populationbased data (Table 1). As far as we know, only two publications include the incidence of SNMM. One was a study by Chiu and Weinstock ${ }^{(13)}$ drawn from nine regional registries representing about $10 \%$ of the population in USA. In the total of 182 patients, including those with oral melanomas, the annual incidence amounted to $0.018 / 105$ individuals. The second was a study by Gal et al., ${ }^{(14)}$ that covered 17 regional registries in USA with $26 \%$ of the population and yielded a yearly incidence of $0.05 / 105$ individuals. In the report of Gal et al., the five-year survival rate was $24.2 \%$. A third study of 115 SNMM patients ${ }^{(15)}$ from a single US registry reported a five-year survival rate of $31 \%$ (Table 1) but did not cite annual incidence.

In Sweden, we have the unique opportunity to document incidence trends and the prognosis of SNMMs, because reporting to the National Swedish Cancer Registry (NSCR) is compulsory for all treating clinicians and pathologists. Therefore, our investi- gation included all SNMMs in Sweden registered during 1960 through 2000.

\section{Materials and methods}

Subjects

Patients were identified at the National Swedish Cancer Registry (NSCR) established in 1958 by the National Board of Health and Welfare. By law, all clinicians, pathologists, or cytologists diagnosing a primary case of cancer must file a report. The NSCR covers approximately $96 \%$ of all cancer cases diagnosed in Sweden ${ }^{(16,17)}$. Diagnostic codes for inclusion were numbered 160.0, $160.2,160.7,160.8$ and 160.9 according to the ICD-7, and only patients with a histopathologic code of malignant melanoma ( $\mathrm{n}$ $=176$ ) were included. All patients were checked in the NSCR for the occurrence of additional primary CMMs that could indicate metastatic disease. None was found.

We, thus, identified all patients with primary SNMM in Sweden during 1960 - 2000, via the NSCR. All their clinical records and pathology reports were then collected throughout Sweden, with the exception of 11 patients whose medical records were not retrievable. Three patients were excluded due to erroneous sites of diagnosis; i.e., one patient had a melanoma of the hard palate, one had a CMM of the vestibulum nasi, and one had a preliminary diagnosis of melanoma, which on review was changed to anaplastic tumour of unknown origin. Furthermore, two patients were included whose initial diagnosis erroneously was coded as malignant melanoma of the epipharynx and the palate, both ICD-7 code 146. Those melanomas originated in the inferior turbinate and the nasal cavity, respectively. Altogether 186 cases of primary SNMM were included after the corrections described above.

Table 1. Sinonasal melanoma survival rates from published reports including $>50$ patients.

\begin{tabular}{|c|c|c|c|c|c|c|}
\hline Author & Period & 5-year survival & no of patients & Case definition & Method & Source of patient series \\
\hline $\begin{array}{l}\text { Moreno et al. } \\
2010\end{array}$ & 1993-2004 & 39 & 58 & $\begin{array}{l}\text { sinonasal } \\
\text { all stages }\end{array}$ & $\begin{array}{l}\text { overall, } \\
\text { Kaplan-Meier }\end{array}$ & One center, Texas, USA \\
\hline $\begin{array}{l}\text { Prasad et al. } \\
2003\end{array}$ & 1956-1999 & 37 & 59 & $\begin{array}{l}\text { sinonasal } \\
\text { all stages }\end{array}$ & $\begin{array}{l}\text { disease specific, } \\
\text { Kaplan-Meier? }\end{array}$ & $\begin{array}{l}\text { One center, New York, } \\
\text { USA }\end{array}$ \\
\hline $\begin{array}{l}\text { Dauer et al. } \\
2008\end{array}$ & $1955-2003$ & 22 & 61 & $\begin{array}{l}\text { sinonasal } \\
\text { all stages }\end{array}$ & $\begin{array}{l}\text { tumour specific, } \\
\text { Kaplan-Meier }\end{array}$ & $\begin{array}{l}\text { One Center, Minnesota, } \\
\text { USA }\end{array}$ \\
\hline $\begin{array}{l}\text { Thompson et al. } \\
2003\end{array}$ & 1970-1995 & 31 & 115 & $\begin{array}{l}\text { sinonasal } \\
\text { all stages }\end{array}$ & $\begin{array}{l}\text { disease-free } \\
\text { Kaplan-Meier? }\end{array}$ & $\begin{array}{l}\text { One registry, Washington, } \\
\text { USA }\end{array}$ \\
\hline $\begin{array}{l}\text { Lund et al. } \\
2012\end{array}$ & $1963-2010$ & 28 & 115 & $\begin{array}{l}\text { sinonasal } \\
\text { all stages }\end{array}$ & $\begin{array}{l}\text { actuarial } \\
\text { Kaplan-Meier }\end{array}$ & $\begin{array}{l}\text { One center, London, } \\
\text { England }\end{array}$ \\
\hline $\begin{array}{l}\text { Chiu, Weinstock } \\
1996\end{array}$ & 1973-1991 & $25( \pm 4)$ & 182 & $\begin{array}{l}\text { oronasal } \\
\text { all stages }\end{array}$ & $\begin{array}{l}\text { overall, } \\
\text { Cox regression }\end{array}$ & $\begin{array}{l}9 \text { population-based registries, } \\
\text { USA }\end{array}$ \\
\hline $\begin{array}{l}\text { Gal et al. } \\
2011\end{array}$ & 2000-2007 & 24 & 304 & $\begin{array}{l}\text { sinonasal } \\
\text { all stages }\end{array}$ & $\begin{array}{l}\text { overall, } \\
\text { Kaplan-Meier }\end{array}$ & $\begin{array}{l}17 \text { population-based registries, } \\
\text { USA }\end{array}$ \\
\hline
\end{tabular}


Table 2. Long-term rhinoflowmetry.

\begin{tabular}{|c|c|}
\hline Patient characteristics & All patients $(n=186)$ \\
\hline Age & Years \\
\hline Range & $31-93$ \\
\hline Mean & 71.3 \\
\hline Median & 72 \\
\hline \multicolumn{2}{|l|}{ Disease specific survival } \\
\hline Median & 21 months \\
\hline Male & 16.8 months \\
\hline Female & 30.5 months \\
\hline TNM/Stage & n (\%) \\
\hline T3 & $116(62.4)$ \\
\hline T4a & $49(26.3)$ \\
\hline $\mathrm{T} 4 \mathrm{~b}$ & $3(1.6)$ \\
\hline Unknown & $18(9.7)$ \\
\hline Only N+ & $4(2.2)$ \\
\hline Only M+ & $6(3.2)$ \\
\hline Both $\mathrm{M}+$ and $\mathrm{N}+$ & $2(1.1)$ \\
\hline Unknown & $18(9.7)$ \\
\hline Stage I & $156(83.9)$ \\
\hline Stage II & $4(2.2)$ \\
\hline Stage III & $8(4.3)$ \\
\hline Unknown & $18(9.7)$ \\
\hline
\end{tabular}

\section{Patient characteristics \\ All patients $(n=186)$}

Gender

Females $102(55)$

Males

$84(45)$

Symptoms

Epistaxis

$95(51.1)$

Obstructive symptoms $\quad 46(24.7)$

Facial swelling $8(4.3)$

Diplopia, exophthalmos, $\quad 9(4.7)$

piphora ptos

Unknown

$28(15.1)$

Localization, anatomical site

Septum 31 (16.7)

Inferior turbinate $\quad 33(17.7)$

Medial turbinate $6(3.2)$

Both inferior and medial $\quad 5(2.7)$

turbinate

Basal nasal cavity 7 (3.8)

Ethmoid sinus $21(11.3)$

Maxillary sinus $\quad 22(11.8)$

Spread growth $\quad 36(19.4)$

Undefined $3(1.6)$

Unknown $22(11.8)$
Each individual had a positive histopathological diagnosis of melanoma. Cases before the 1980s were usually supplemented with the Masson silver staining to sustain the presence of melanin pigment, later on also immune markers like S-100 and HMB45 were used for establishing the melanoma diagnosis. We scrutinized all pathology reports. In 90 of the 186 cases, we also reviewed the histological sections.

Most cases in this report were amelanotic (see below). Amelanosis was here defined as macroscopic/clinical amelanosis. Properly, the microscopic examination often revealed sparse melanin pigment in occasional cells even in these macroscopically amelanotic melanomas. Besides, in melanomas without detectable pigment immune markers sustained the melanoma diagnosis.

Information extracted from the NSCR included standard demographic data such as age at diagnosis, gender, patient's residence, treating hospital, date of diagnosis as well as overall survival time. From the clinical records we extracted diagnoses, symptoms, TNM classification and Stage, disease site, mode of treatment, five-year local control, and tumour-specific survival rate. When data could not be appropriately determined, they were coded as missing.

We used the classification from the seventh edition of the TNM Classification of Malignant tumours from UICC (International Union Against Cancer) (2009) when comparing the outcome of the disease. Staging was done according to Ballantyne's clinical system, in which Stage I represents localized tumour, Stage II tumour with regional metastasis, and Stage III tumour with distant metastasis (18).

The records were used by permission from the Research Ethics Board of the Karolinska Institute.

\section{Statistical analysis ${ }^{(19,20)}$}

The patients were divided into eight groups according to age at diagnosis, each spanning ten years, except for the youngest ( 0 - 24 years) and oldest ( $\geq 85$ years). The calendar period was 


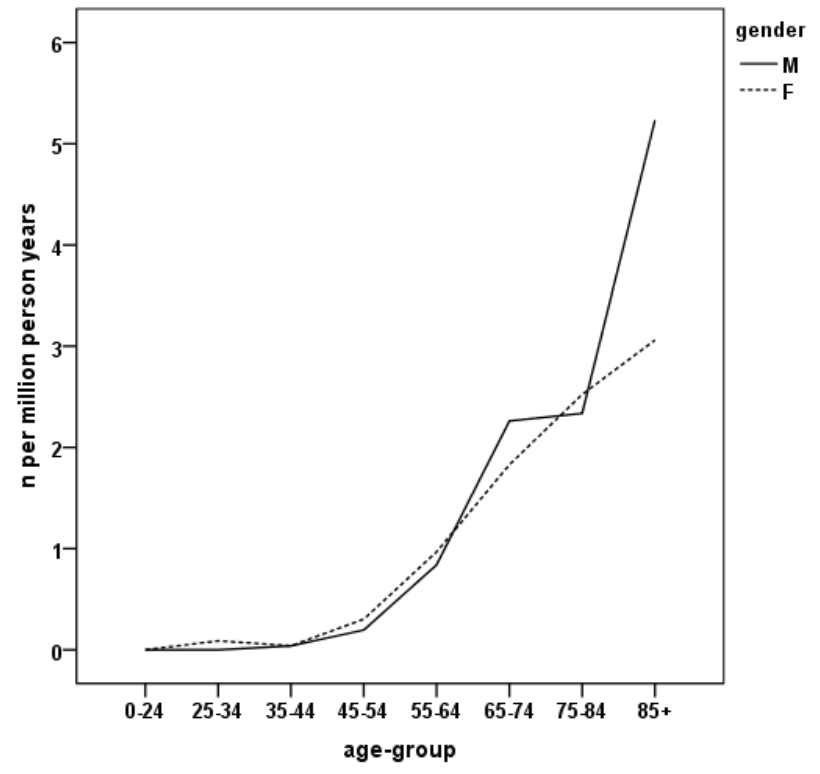

Figure 1. The increased incidence of SNMM by patient age in Sweden during the time period $1960-2000$.

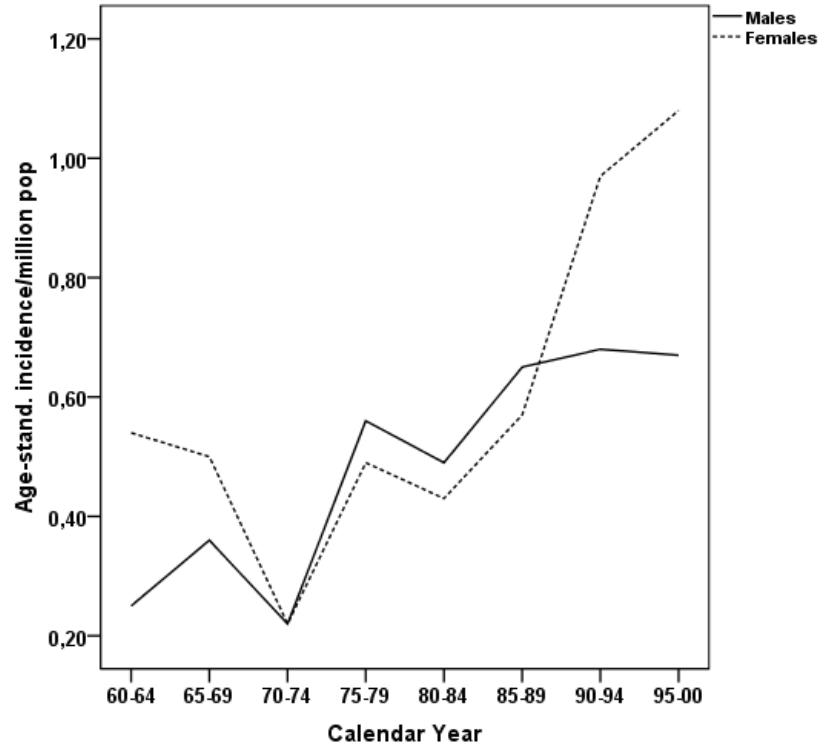

Figure 2. The overall increase of SNMM in Sweden during the time period 1960 - 2000 divided into five-year-segments beginning in 1960, except the period from 1995 - 2000. Incidence was analysed by date and gender, employing age standardisation, so that the absolute incidence was represented for each calendar year. The age distribution in Sweden 1980-1984 was used as a standard. Changes in the annual age-standardized incidence rates were examined by calculating the average annual percentage change over a time period. Straight lines were fitted to the standardised incidence by least squares regression. The slopes were estimated from these fitted lines.

The annual incidence of SNMM per million inhabitants and the population density in the 24 counties of Sweden were analysed by linear regression with the method of least squares. The population 1980 - 1984 in each county was used as a background population. The definition of population density, as given by Statistics Sweden ${ }^{(19)}$, is based on population centres.

Survival rates were estimated with the life table method, taking censored observations into account. The cut-off date for followup was 24th of February 2011. Tumour-specific survival was analysed.

\section{Results}

\section{Patients}

The 186 individuals in this series included 102 (55\%) women and 84 (45\%) men. Their ages ranged from 31 to 93 years, with a mean age of 71.3 and a median age of 72 at diagnosis (Table 2). All patients were Caucasians, according to the information in their medical records.

We were able to classify TNM and Stage for 168 of the 186
SNMM patients but not for 18 whose records were insufficient for classification (Table 2). Overall, 92.9\% (156/168) of the SNMM tumours presented in Stage I. Thus, only a small minority of $7.1 \%$ $(12 / 168)$ was diagnosed in Stages II or III.

The mean age-specific incidence of SNMM increased with age peaking after the eightieth year in both genders (Figure 1). During the study period, there was no significant increase or decrease in age-specific incidence in any age group.

The age-standardized incidence of SNMM showed a significant increase for both genders during the investigated period. For females the average annual age-standardized incidence per million population increased from 0.54 1960-1964 to 1.08 during 1995 - 2000. The corresponding figures for males were 0.25 and 0.67 , respectively. A more rapid increase in incidence was noted among males than females (Figure 2), although this difference was not significant.

\section{Geographic distribution}

No correlation between population density and the incidence of SNMM could be detected (Figure 3). Similarly, age-standardised incidence and population density showed no correlation. As to geographic locale, one specific county, the island of Gotland, showed an unambiguously higher incidence of SNMM than all other counties.

\section{Symptoms at diagnosis}

The symptoms of the patients at their first visit to the clinician were mixed, mainly nonspecific but referable to the tumour site (Table 2). Epistaxis was the most frequent symptom; nasal 


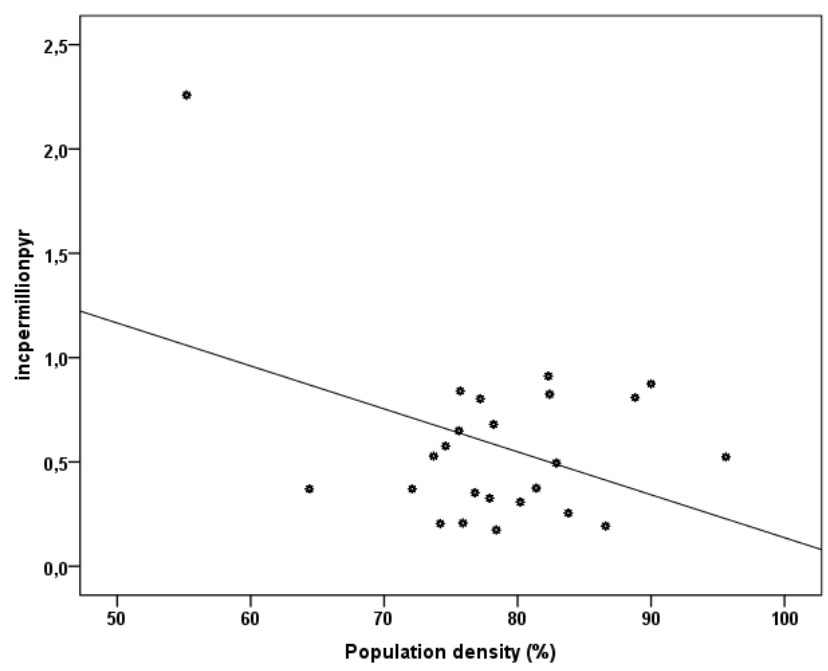

Figure 3. The incidence of SNMM in Sweden 1960 - 2000 in multiple counties.

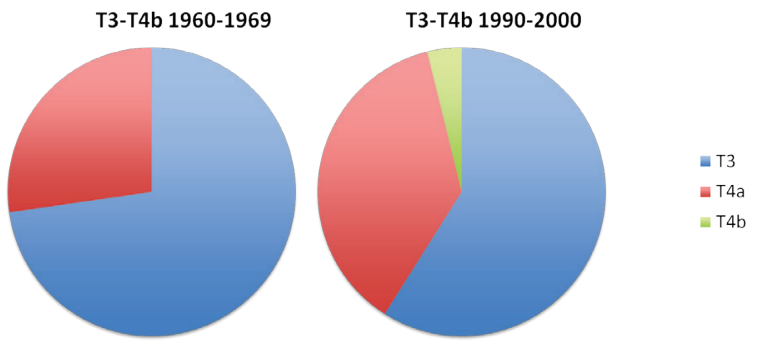

Figure 4. The difference in tumour extent in cases diagnosed in the 1960 's compared to 1990 's. obstruction was the second, followed by facial swelling due to a locally advanced tumour. The interval from the onset of symptoms to the time of diagnosis was not possible to estimate accurately from the clinical records.

\section{Tumour site}

In total, $44.1 \%$ of the tumours involved the nasal cavity, and 23.2\% affected the sinuses (Table 2). The most frequent nasal site was the inferior turbinate, followed by the septum (20.1 and $18.9 \%$, respectively). Among $34.4 \%$ of the patients, the point of origin was indeterminate due to growth both in the nasal cavity and sinuses (19.4\%) or because the original site was not specified in the records (13.3\%). Gender made no difference in localization.

\section{Clinical and pathological features}

The vast majority $(70.9 \%)$ of these patients presented with an amelanotic tumour. A minority, 34.8\%, initially had amelanotic polyps. Among those with ulcerated tumours ( $41.1 \%$ of all tumours), only 3 patients ( $4.6 \%$ of the ulcerated tumours) manifested macroscopic pigmentation.

With increasing time during the 41-year study period, the patients tended to present with more advanced disease (Figure 4). Among the 156 patients whose tumours were classed as Stage I, 45 (28.8\%) developed recurrent disease within one year of diagnosis. For most of them (57.8\%), the disease remained localized; however, $17.8 \%$ developed regional metastases and 24.4\% distant metastases.

The median time to local recurrence was 23 months, and times to regional and distant metastasis were 11 and 8 months, respectively. However, two patients developed late local recurren- ces, one $>10$ years and the other 9 years and 9 months after the primary diagnosis.

\section{Histopathology}

Initially, $20.9 \%$ of the patients were mis-diagnosed, and the tumour labelled as a type other than SNMM, for example, poorly differentiated squamous cell carcinoma, olfactory neuroblastoma, lymphoma, or sarcoma. Subsequently, though, these erroneous diagnoses were corrected. The mis-diagnoses were usually based on small biopsies and were revised after secondary extended surgery when additional, more appropriate material was available for analysis.

\section{Treatment}

The most common primary therapy was surgery alone, which was performed in $53.1 \%$ of the 186 patients, followed by surgery combined with pre- or postoperative radiotherapy in $32.0 \%$. Surgery combined with radio-chemotherapy was used in rare instances, $2.7 \%$. The surgical procedures varied from local wide excision to total maxillectomy with orbital exenteration (removal of the eye). Just $17.8 \%$ of the patients were treated with local excision, whereas the operations of $47.4 \%$ were done according to Denker (excision of the anterior and medial wall, including the medial and inferior turbinates, of the maxillary sinus); $26.7 \%$ received a total maxillectomy alone, and $8.1 \%$ underwent maxillectomy and exenteration. In $12.2 \%$, treatment was restricted to chemotherapy, radiation, or partial resection of the tumour, with palliative intent, or no antitumoural treatment. For 39 patients (20.9\%), information concerning treatment was missing or incomplete and, accordingly, not useful for analysing the outcome of specific therapeutical modalities. 
Of the patients in Stage II, 1 of 4 underwent neck dissection surgery and postoperative chemo/radiotherapy, with curative intent. However, one year later, the tumour recurred with distant metastases to the lungs and skeleton. The other 3 patients in Stage II received only palliative treatment, due to inoperable tumours. The patients in Stage III were all treated palliatively, because the tumours and metastases were considered ineligible for antitumoural therapy.

\section{Survival}

The cut-off date for follow-up was February 24, 2011. No patients were lost to follow-up. The follow-up time ranged from 0 to 283 months for patients who eventually died and 148 - 172 months for living patients. The tumour-specific five-year survival rates were $20.4 \%$ for all patients. However, women had significantly better survival rates than men $(p=0.038)$ (Figure 5$)$. Patients over 60-years-old at diagnosis died significantly earlier $(p=0.040)$ than younger patients. However, five years after diagnosis, there was no difference in the length of survival. Patients with epistaxis had a better prognosis than those with only nasal congestion ( $p=0.046)$.

The choice of primary treatment for patients in Stage I did not have a significant impact on outcomes in terms of time to relapse or tumour-specific survival. However, during the 41-year period the term of survival increased significantly $(p=0.024)$ irrespective of therapy.

\section{Discussion}

Although the number of sinonasal malignancies in general has decreased over the last decades in Sweden ${ }^{(8)}$, we now demonstrate a significantly increased incidence of SNMM, which has not been reported before. Many reasons for this increased incidence are possible, but improved diagnostic methods must have some impact. Presumably, new diagnostic tools like immunohistochemical markers have increased the accuracy of identifying SNMM during the prolonged time period this investigation covered. Such markers are of particular importance, since over $30 \%$ of the patients with SNMM displayed non-pigmented tumours ${ }^{(15)}$. In our series, including about $70 \%$ clinically amelanotic melanomas, about $20 \%$ were primarily mis-diagnosed as low- or undifferentiated malignancies. However, a reduction of diagnostic error is too simple an explanation, since it does not account for the significant difference in incidence between males and females.

We found a significantly higher overall incidence of SNMM for females than males, but with a more rapid increase among males, again without any known cause. Interestingly, females also had a higher incidence of ano-rectal melanomas ${ }^{(3)}$. In contrast, males, not females, predominated in statistics reporting other sinonasal malignancies ${ }^{(8,21)}$. Furthermore, the incidence of CMM in Sweden was similar in both genders ${ }^{(22)}$.

In Sweden, all other sinonasal malignancies except SNMM have decreased in incidence since 1970, and the reason for this is also unclear ${ }^{(8,21)}$. In comparison, the incidence of CMM in Sweden and in the other Nordic countries increased rapidly in both genders over the last 40 years ${ }^{(22,23)}$.

Obviously, the incidence of SNMMs was low compared to CMMs. It is generally agreed that UV radiation is a main causative factor of CMM, but the aetiology/pathogenesis of SNMM is unknown, as is also true for other melanomas in the mucosal membranes.

Air pollution could be a contributor to the increasing incidence of SNMM ${ }^{(11,24)}$. Accordingly, a report published in 2000 described an increase of paranasal malignancies, including SNMM in Mexico City, suggesting that the heavy air pollution there could be responsible ${ }^{(11)}$.

Research has indicated that environmental carcinogens and drugs are filtered by and conjugated to melanins, sometimes over a long time period. Examples include aflatoxin B1, benzidine, and polycyclic hydrocarbons, such as dimetylbenzanthracene and benzopyrene ${ }^{(25)}$. Furthermore, human melanocytes are capable of metabolizing benzopyrene to any of several metabolites, including the carcinogen benzopyrene-7,8-diol (26). The turbinates and nasal septum are the most frequently affected subsites, suggesting that an inhaled carcinogen could be a cause, since most inhaled air passes through the nasal cavity, particularly the septum and inferior turbinates, during normal breathing.

However, we found no connection between the incidence of SNMM and the population density of regions in Sweden, which could dispute any important impact of air pollution in urban areas. An interesting outlier, though, was the much higher incidence of SNMM on the isle of Gotland in the Baltic Sea than in other parts of Sweden. This small island was sparsely populated and lacked urban environments, so this finding may be a random event influenced strictly by chance.

Occupational factors may also contribute to SNMM as is suggested by Holmström et al. who found that occupational exposure for formaldehyde might cause SNMM ${ }^{(24)}$. Unfortunately, information on possible occupational and environmental factors was not available in this series.

The most common site of origin of SNMM was the inferior turbinate followed by the septum, but among $34.4 \%$ of the patients, the site of origin was indeterminate due to growth both in the nasal cavity and sinuses or because the original site was not specified in the records. The explanation for this high percentage of indeterminate origin of the tumour could be patient's and/ or doctor's delay. Accordingly, when the tumour was eventually diagnosed it was often advanced and the origin was difficult to 
determine.

The treatment of choice for patients with SNMM in Stages I-II is complete tumour excision, but the anatomical complexity and the vulnerable structures close to the nasal- and paranasal cavities make complete resection difficult. In our series, we found that the type of surgery was based on the tumour site and varied from local excisions to extended surgery. One must always consider selection bias even though all patients who we compared were in clinical Stage 1. The methods for identifying metastases varied among the 60 hospitals involved and also changed over time. The sophisticated techniques of today, including CT scanning, MRT, and PET/CT scanning, were not available during the beginning of the study's time period. This technological change could account for an apparent increase in the number of more advanced tumours identified in the later part of the study period, in turn, perhaps causing Stage migration. Newer treatment strategies should certainly be responsible for the prolonged survival of Stage I patients, and modern diagnostic tools have facilitated a more accurate staging of each patient as well as greater precision of therapy, although the current study did not measure that possibility.

The prognosis for SNMM patients of both genders was dismal; nevertheless, women had significantly better survival statistics than men. Furthermore, patients with ano-rectal melanomas in Sweden display the same gender-associated difference in survival ${ }^{(3)}$. This is also true for CMM in Sweden ${ }^{(27)}$ and in other countries ${ }^{(18,28)}$. Additionally, multifactorial analyses have shown that gender is an independent prognostic factor for CMM ${ }^{(23)}$. Regardless of the reason, male patients generally had more advanced tumours at diagnosis than women ${ }^{(29)}$.

SNMM was a more lethal disease in older than in younger patients during the first five years after diagnosis. However, five years or more after diagnosis, no difference remained in survival time between age groups. An age-related decline of immunologic forces may be a partial cause; alternatively, standard therapy may not be instituted because of an elder's weak physical condition or refusal of extensive treatment ${ }^{(18,30)}$.

Usually the initial symptoms of SNMM are nonspecific and do not cause the patients to seek immediate medical care. In fact, patients with epistaxis had a significantly better prognosis than those with only nasal congestion. A simple explanation might be that the patients considered epistaxis more alarming than congestion and thus sought medical examination sooner. In the majority of patients, the tumour appeared as a clinically amelanotic growth and, often, as an amelanotic polyp. Such lesions are easily mistaken for a benign disease, which clinicians should keep in mind to avoid a harmful 'doctor's delay.' Therefore, a solitary non-pigmented polyp in the nasal cavity always requires removal as well as biopsy for histopathological investigation.

The finding of tumours localized both to the nasal cavity and the paranasal sinuses indicated a locally advanced malignity, as previously suggested ${ }^{(15)}$. The reason(s) for the diagnosis with advanced local tumours could be late detection ("hidden" tumour site, or patients' or doctor's delay) or inherent biological aggressiveness of this kind of melanomas.

In our series, different therapeutic strategies did not seem to have any significant impact on time to recurrence or diseasespecific survival. It is difficult to draw any firm conclusions, because there was no systematic treatment or follow-up for these patients in our study. Additionally, the small numbers of patients in recent studies, including our own, or a possible selection bias within patient series make it difficult to draw firm conclusions as to the outcome of melanoma disease in terms of treatment modalities. The choice of surgical approach and presence or absence of cervical metastases is a controversial issue regarding the influence on outcome ${ }^{(31)}$. A recent study by Lund et al., showed that radiotherapy did not improve the local control or survival of patients with SNMM. They also found that cervical metastases conferred a dramatically worse outcome ${ }^{\text {(32). }}$ Another recent study showed that postoperative radiotherapy improved loco regional control when a higher total dose is used (33). Furthermore, there are other reports that emphasize the advantage of adjuvant radiotherapy ${ }^{(34,35)}$. However, because of the small series in most reports the impact of various strategies of treatment on disease control and survival is difficult to assess.

SNMM is second only to squamous cell carcinoma among primary malignancies of the nasal region. The presence of regional lymph node metastases at presentation was rare in our study (3.3\%) compared to squamous cell cancer (10\%) (7). In contrast, haematogenous metastases were more frequent among patients with SNMM than squamous cell carcinomas, which is in accordance with the greater haematogenous dissemination of melanomas.

The value of retrospective analysis of any diagnosis is often uncertain in modern management of human disease. When a rare neoplasm such as SNMM is studied, one must be aware of the risk that analysis may be inexact or incomplete. However, the accumulated experience from examining many cases in national population-based series has the power to uncover features that the individual case study or case series may overlook. In studies of rare malignancies, population-based and unbiased series are the only sources of appropriate information on disease patterns and outcomes of therapy modalities.

In summary, SNMM is a rare disease; however, its trend of an increasing incidence during the last decades is noteworthy. 
The incidence of SNMM was for unknown reasons significantly higher among women than men. We found no geographic accumulation of SNMM in densely populated urban environments with a probability of increased air pollution. Despite the poor prognosis, although better for women than for men, the five-year, tumour-specific survival rate improved significantly for both genders during the period evaluated here.

\section{Acknowledgements}

The authors express their gratitude to Bo Nilsson for advice and help with statistical analyses, Drs Lena Kanter and Lars Olding for help with the histopathological review, and Phyllis Minick for editorial assistance. The investigation was supported by the
Radiumhemmet Research Funds, the Swedish Cancer Society and grants from the Stockholm County Council (ALF-funding) and the ACTA Otolaryngologica Foundation.

\section{Authorship contribution}

The contribution to the planning and design, acquisition of data was made by MJ and BR-O. The interpretation and analysis of data, drafting and revising of the article was made by all 3 authors.

\section{Conflict of interest}

No conflict of interest.

\section{References}

1. Ragnarsson-Olding $B$, Johansson $H$, Rutqvist LE, Ringborg U. Malignant melanoma of the vulva and vagina. Trends in incidence, age distribution, and long-term survival among 245 consecutive cases in Sweden 19601984. Cancer. 1993; 71: 1893-1897

2. Weinstock MA. Malignant melanoma of the vulva and vagina in the United States: patterns of incidence and population-based estimates of survival. Am J Obstet Gynecol. 1994; 171: 1225-1230.

3. Ragnarsson-Olding BK, Nilsson PJ, Olding LB, Nilsson BR. Primary ano-rectal malignant melanomas within a population-based national patient series in Sweden during 40 years. Acta oncologica. 2009; 48: 125-131.

4. Cagir B, Whiteford MH, Topham A, Rakinic J, Fry RD. Changing epidemiology of anorectal melanoma. Dis Colon Rectum 1999; 42 1203-1208.

5. The Swedish National Cancer registry Cancer incidence in Sweden, 1960-2000. National Board of Health and Welfare.

6. Grau C, Jakobsen MH, Harbo G, et al. Sinonasal cancer in Denmark 1982-1991--a nationwide survey. Acta Oncol. 2001; 40: 19-23.

7. Harbo G, Grau C, Bundgaard T, et al. Cancer of the nasal cavity and paranasal sinuses. A clinico-pathological study of 277 patients. Acta Oncol. 1997; 36: 45-50.

8. Norlander T, Frodin JE, Silfversward C, Anggard A. Decreasing incidence of malignant tumors of the paranasal sinuses in Sweden. An analysis of 141 consecutive cases at Karolinska Hospital from 1960 to 1980. Ann Otol Rhinol Laryngol. 2003; 112: 236-241.

9. Zak FG, Lawson W. The presence of melanocytes in the nasal cavity. Ann Otol Rhinol Laryngol. 1974; 83: 515-519.

10. Gandini S, Sera F, Cattaruzza MS, et al. Metaanalysis of risk factors for cutaneous melanoma: II. Sun exposure. Eur J Cancer. 2005; 41: $45-60$

11. Calderon-Garciduenas L, Delgado R,
Calderon-Garciduenas A, et al. Malignant neoplasms of the nasal cavity and paranasal sinuses: a series of 256 patients in Mexico City and Monterrey. Is air pollution the missing link? Otolaryngol Head Neck Surg. 2000; 122: 499-508

12. Lücke A. Die Lehre von den Geschwuksten in anatomischer und klinischer Beziehung in Handbuch d. allg u. spec. chir. Erlangen. 1869: 244.

13. Chiu NT, Weinstock MA. Melanoma of oronasal mucosa. Population-based analysis of occurrence and mortality. Arch Otolaryngol Head Neck Surg. 1996; 122: 985-988.

14. Gal TJ, Silver N, Huang B. Demographics and treatment trends in sinonasal mucosal melanoma. Laryngoscope. 2011; 121: 20262033.

15. Thompson LD, Wieneke JA, Miettinen M Sinonasal tract and nasopharyngeal melanomas: a clinicopathologic study of 115 cases with a proposed staging system. Am J Surg Pathol. 2003; 27: 594-611.

16. Mattsson B, Wallgren A. Completeness of the Swedish Cancer Register. Non-notified cancer cases recorded on death certificates in 1978. Acta Radiol Oncol. 1984; 23: 305313

17. Barlow L, Westergren K, Holmberg L, Talback M. The completeness of the Swedish Cancer Register: a sample survey for year 1998. Acta Oncol. 2009; 48: 27-33.

18. Ballantyne AJ. Malignant melanoma of the skin of the head and neck. An analysis of 405 cases. Am J Surg. 1970; 120: 425-431.

19. Statistical Yearbook of Sweden. Publication Services Statistics, Sweden, Annual Publications. Örebro.

20. Draper, N. R. and Smith, H. Applied Regression Analysis, Wiley, New York, 1980

21. The Swedish National Cancer registry. Cancer incidence in Sweden, 1970-2009. National Board of Health and Welfare.

22. Mansson-Brahme $E$, Johansson H, Larsson O, Rutqvist LE, Ringborg U. Trends in incidence of cutaneous malignant melanoma in a Swedish population 1976-1994. Acta
Oncologica. 2002; 41: 138-146.

23. Tryggvadottir L, Gislum M, Hakulinen T, Klint A, Engholm G, Storm HH, Bray F. Trends in the survival of patients diagnosed with malignant melanoma of the skin in the Nordic countries 1964-2003 followed up to the end of 2006. Acta Oncologica. 2010; 49: 665-672.

24. Holmstrom M, Lund VJ. Malignant melanomas of the nasal cavity after occupational exposure to formaldehyde. $\mathrm{Br} J$ Ind Med. 1991; 48: 9-11.

25. Roberto A, Larsson BS, Tjalve H. Uptake of 7,12-dimethylbenz(a)anthracene and benzo(a)pyrene in melanin-containing tissues. Pharmacol Toxicol. 1996; 79: 92-99.

26. Agarwal R, Medrano EE, Khan IU, Nordlund JJ, Mukhtar H. Metabolism of benzo[a] pyrene by human melanocytes in culture. Carcinogenesis. 1991; 12: 1963-1966.

27. Cohn-Cedermark G, Mansson-Brahme E, Rutqvist LE, et al. Trends in mortality from malignant melanoma in Sweden, 19701996. Cancer. 2000; 89: 348-355.

28. Chang AE, Karnell LH, Menck HR. The National Cancer Data Base report on cutaneous and noncutaneous melanoma: a summary of 84,836 cases from the past decade. The American College of Surgeons Commission on Cancer and the American Cancer Society. Cancer. 1998; 83: 1664-1678.

29. de Vries E, Nijsten TE, Visser O, et al. Superior survival of females among 10,538 Dutch melanoma patients is independent of Breslow thickness, histologic type and tumor site. Ann Oncol. 2008; 19: 583-589.

30. Iversen K, Robins RE. Mucosal malignant melanomas. Am J Surg. 1980; 139: 660-664.

31. Lund VJ, Howard DJ, Harding L, Wei WI. Management options and survival in malignant melanoma of the sinonasal mucosa. Laryngoscope. 1999; 109: 208-211.

32. Lund VJ, Chisholm EJ, Howard DJ, Wei WI. Sinonasal malignant melanoma: an analysis of 115 cases assessing outcomes of surgery, postoperative radiotherapy and endoscopic resection. Rhinology. 2012; 50: 203-210. 
33. Moreno MA, Roberts DB, Kupferman ME, et al. Mucosal melanoma of the nose and paranasal sinuses, a contemporary experience from the M.D. Anderson Cancer Center Cancer. 2010; 116: 2215-2223.

34. Dauer EH, Lewis JE, Rohlinger AL, Weaver $A L$, Olsen KD. Sinonasal melanoma: a clinicopathologic review of 61 cases. Otolaryngol Head Neck Surg. 2008; 138: 347-352.

35. Kingdom TT, Kaplan MJ. Mucosal melanoma of the nasal cavity and paranasal sinuses. Head Neck. 1995; 17: 184-189.
Mattias Jangard, MD

Department of Oto-Rhino-Laryngo-

logy,

Head and Neck Surgery

Karolinska University Hospital

17176 Stockholm

Sweden

Tel: +46-8-5177 9817

E-mail: mattias.jangard@karolinska.se 